\title{
Protective effect of Ginkgo flavonoids, amifostine, and leuprorelin against platinum-induced ovarian impairment in rats
}

\author{
Z. Chang, H.L. Wang and H. Du
}

Department of Gynaecology and Obstetrics, the Second Hospital of Hebei Medical University, Shijiazhuang, Hebei, China

Corresponding author: H.L. Wang

E-mail: huilanwangcn@126.com

Genet. Mol. Res. 13 (3): 5276-5284 (2014)

Received April 26, 2013

Accepted December 5, 2013

Published July 24, 2014

DOI http://dx.doi.org/10.4238/2014.July.24.6

\begin{abstract}
Platinum-induced ovarian impairment is a consequence of treatment for malignant ovarian tumors. We compared the protective effects of Ginkgo flavonoids, amifostine, and leuprorelin on ovarian impairment in rats. Fifty rats were randomly divided into the A, B, C, D, and E groups, which were given saline, cisplatin, cisplatin plus Ginkgo flavonoids, cisplatin plus amifostine, and cisplatin plus leuprorelin, respectively. Ovarian weight was significantly greater in groups $C$ and $D$ compared with group B $(83.5 \pm 6.7$ and $86.8 \pm 10$ vs $56.8 \pm 5.4 \mathrm{mg})$. The total follicle numbers were higher in groups $\mathrm{C}, \mathrm{D}$, and $\mathrm{E}$ than in group $\mathrm{B}(60.5 \pm 3.9$, $63.8 \pm 5.1$, and $67.7 \pm 3.5 v s 49.6 \pm 4.5$ ), and the apoptotic index was reduced in groups $\mathrm{C}, \mathrm{D}$, and $\mathrm{E}$ compared with group $\mathrm{B}(35.7 \pm 2.0,37.4 \pm$ 1.6 , and $30.5 \pm 2.9$ vs $65.3 \pm 2.9 \%$ ). The ovaries in groups $\mathrm{B}, \mathrm{C}$, and $\mathrm{D}$ had higher protein and mRNA expression levels of cytoplasmic Cytochrome c (Cyt-c) and apoptotic protease activating factor-1 (Apf-1) compared to group A; the Cyt-c mRNA expression was five-fold higher. The mRNA expression of Cyt-c and Apf-1 were significantly lower in groups C, D, and $\mathrm{E}$ compared with group B. Administration of leuprorelin, flavonoids, or amifostine protected rats against the ovarian impairment induced by
\end{abstract}


prior intraperitoneal injection of cisplatin. The efficacy of leuprorelin was superior to that of Ginkgo flavonoids and amifostine, but there was no difference between the effects of Ginkgo flavonoids and amifostine.

Key words: Platinum-induced ovarian impairment; Ginkgo flavonoids; Amifostine; Leuprorelin

\section{INTRODUCTION}

Malignant ovarian germ cell tumor (MOGCT) is a malignancy derived from embryonic gonads. Although the incidence is low, this tumor is prevalent in children and adolescents, and many of these patients wish to have their own children later in life. Resection surgery combined with postoperative chemotherapy is highly effective in treating this type of tumor, and the five-year survival rate can reach $90 \%$ after combination chemotherapy. However, chemotherapy results in ovarian dysfunction, ovarian atrophy, and reduced follicular storage, along with menstrual disorders, amenorrhea, infertility, a decline in the quality of sex life, and even premature ovarian failure, which seriously affect the patient's quality of life and reproductive function. Many research efforts have focused on various approaches to protect the ovaries from chemotherapy-induced impairment. A number of pilot studies have demonstrated the protective effects of gonadotropin-releasing hormone $(\mathrm{GnRH})$ analogues on ovarian function (Camats et al., 2009; Ozcelik et al., 2010). It has been shown that flavonoids can antagonize oxidation, inhibit apoptosis, and reverse chemotherapeutic drug resistance (Babich et al., 2009; Pinto et al., 2009; Liu et al., 2009). Amifostine, as a cytoprotective agent, has been reported to exert protective effects on multiple organs in the course of radiotherapy and chemotherapy (Murley et al., 2012). However, whether or not it has any protective effect on ovaries has not been reported. The most commonly used chemotherapy regimens for MOGCT are bleomycin, etoposide, and cisplatin (BEP), cisplatin (EP), and etoposide, cisplatin, and ifosfamide (VIP), in which the major drug that causes ovarian impairment is cisplatin. The mechanism of action involves the induction of apoptosis by oxidative damage, thereby causing a decrease in the number of follicles (Chirino and Pedraza-Caverri, 2009). Recent studies have shown that apoptotic protease activating factor-1 (Apaf-1) constitutes the core of apoptotic bodies (Zou et al., 1997). Cytochrome c (Cyt-c) activates Caspase-9 through binding to and activating Apaf-1, thereby initiating apoptosis (Li et al., 1997). Cyt-c is positioned at the outer surface of the mitochondrial inner membrane. When cells experience oxidative damage, the function of mitochondrial membranes is altered, leading to the release of Cyt-c to the cytoplasm (Rehm et al., 2009) where it binds to Apaf-1 to start the process of apoptosis. In this study, we assessed the expressions of the Cyt-c and Apaf-1 genes by measuring their intra-cytoplasmic protein and mRNA levels, and investigated the molecular mechanisms underlying chemotherapy-induced ovarian impairment.

\section{MATERIAL AND METHODS}

\section{Animals}

Fifty albino Sprague-Dawley rats, aged 12 weeks and weighing $250 \pm 20$ g, were pur- 
chased from the Experimental Animal Center of Hebei Medical University. The rats were fed full-valence pellet feed and provided with free access to food and water. They were maintained at room temperature $\left(20\right.$ to $\left.26^{\circ} \mathrm{C}\right)$ with humidity controlled at $50 \pm 5 \%$. After acclimation for one week, the rats were randomized for experiments.

\section{Randomization and drug administration}

Fifty rats were randomly divided into five groups, with 10 rats in each group. The rats were treated as follows: Group A received $2 \mathrm{~mL}$ saline per rat by intraperitoneal injection for 7 consecutive days; Group B received $2 \mathrm{mg} \cdot \mathrm{kg}^{-1} \cdot \mathrm{day}^{-1}$ cisplatin by intraperitoneal injection for 7 consecutive days; Group C received $1.5 \mathrm{~g} \cdot \mathrm{kg}^{-1} \cdot \mathrm{day}^{-1}$ Ginkgo flavonoids (Dr. Willmar Schwabe $\mathrm{GmbH} \& \mathrm{Co}$.; Karlsruhe, Germany), which was orally administered, and then received 2 $\mathrm{mg} \cdot \mathrm{kg}^{-1} \cdot \mathrm{day}^{-1}$ cisplatin $30 \mathrm{~min}$ later by intraperitoneal injection for 7 consecutive days; Group D received $3 \mathrm{~g} \cdot \mathrm{m}^{2-1} \cdot$ day $^{-1}$ amifostine (Dalian Merro Pharmaceutical Co. Ltd.; Dalian, China) by intraperitoneal injection, and then $2 \mathrm{mg} \cdot \mathrm{kg}^{-1} \cdot \mathrm{day}^{-1}$ cisplatin $30 \mathrm{~min}$ later by intraperitoneal injection for 7 consecutive days; Group E received $0.25 \mathrm{mg} /$ mouse leuprorelin (Beijing Biote Pharmaceutical Co. Ltd.; Beijing, China) by subcutaneous injection, and then $2 \mathrm{mg} \cdot \mathrm{kg}^{-1} \cdot \mathrm{day}^{-1}$ cisplatin 20 min later for 7 consecutive days.

All dosages were based on clinical human dosages. After treatment, the rats were anesthetized by intraperitoneal injections of $40 \mathrm{mg} / \mathrm{kg} 1 \%$ sodium pentobarbital. Vena cava blood was collected, and both ovaries were removed before the animal was sacrificed and weighed. The left ovary was formaldehyde-fixed for follicle counting and apoptosis detection, whereas the right ovary was cut into two pieces, one for the assay of protein levels by Western blot, and the other piece was placed in liquid nitrogen for later RNA extraction.

\section{Follicle count}

The ovaries were fixed in formaldehyde, embedded in paraffin, and serially cut into $5-\mu \mathrm{m}$ sections. One of 10 slides was taken for hematoxylin and eosin (H\&E) staining and observed under a light microscope (Olympus IX70; Hebei Medical University), and the first 100 follicles were counted. Follicle grading standards were as follows: primordial follicles 20-30 $\mu \mathrm{m}$ diameter, growing follicles 30-400 $\mu \mathrm{m}$, and mature follicles $600-700 \mu \mathrm{m}$.

\section{TUNEL assay for apoptosis detection}

The same H\&E-stained slides described above were used for the apoptosis assay following the TUNEL kit instructions (Promega).

After the slides were mounted with anti-fluorescence quenching liquid, they were observed under a fluorescence microscope (Olympus IX70). The excitation wavelength was 450 $\mathrm{nm}$, and the emission wavelength was $550 \mathrm{~nm}$.

To calculate the apoptotic index, 5 microscopic fields of each slide that contained the largest number of apoptotic cells were observed under a fluorescence microscope (x400 magnification). In each field, the positive cells were counted until reaching a total number of 100 cells. The apoptotic index was calculated with the following formula: apoptotic index $=$ number of positive cells/500 x number of apoptotic cells per 100 cells. 


\section{Cytoplasmic Cyt-c and Apaf-1 protein levels by Western blot}

\section{Extraction of cytoplasmic proteins}

Cytosolic proteins were extracted using the Membrane and Cytoplasmic Protein Extraction Kit (\#K0320), following manufacturer instructions.

\section{Protein quantification and staining}

After protein quantification with the Coomassie brilliant blue method, $50 \mu \mathrm{g}$ protein were subjected to sodium dodecyl sulfate-polyacrylamide gel electrophoresis (SDS-PAGE). The target protein was transferred to a polyvinyldifluoride (PVDF) membrane, which was placed on the surface of a solution containing the first antibody (1:2000 dilution Rabbit mAb; Cell Signaling). After incubating overnight at $4^{\circ} \mathrm{C}$, the membrane was further incubated with secondary antibody (1:1000 dilution horseradish peroxidase (HRP)-linked anti-rabbit IgG; Cell Signaling) at room temperature for $2 \mathrm{~h}$ for ECL chemiluminescence detection. The protein content of the target bands was analyzed using a gel image processing system (Shanghai Furi Technology Limited Company; Hebei Medical University).

\section{Expression levels of Cyt-c and Apaf-1 mRNAs by real-time polymerase chain reaction $(\mathbf{P C R})$}

\section{Total RNA extraction}

Trizol reagent was used to extract total RNA from ovarian tissues. The concentration of the RNA was determined, and the RNA purity was confirmed by an optical density $(\mathrm{OD})_{260}$ $\mathrm{OD}_{280}$ ratio between 1.8 and 2.1. The total RNA extracted was stored at $-80^{\circ} \mathrm{C}$ before use.

\section{Reverse transcription to prepare template cDNA}

One microgram total RNA was reverse transcribed to cDNA by using random 9-mers as primers under the action of reverse transcriptase. The total volume of the reaction was 20 $\mu \mathrm{L}$, including $4 \mu \mathrm{L}$ total RNA, $2 \mu \mathrm{L}$ primers, $4 \mu \mathrm{L} 5 \mathrm{X}$ RT buffer, $0.5 \mu \mathrm{L} 20 \mathrm{U}$ RNase Inhibitor, $2 \mu \mathrm{L} 10 \mathrm{mM}$ dNTP mixture, $1 \mu \mathrm{L} 200 \mathrm{U}$ reverse transcriptase, and $40 \mathrm{U} / \mu \mathrm{L}$ RNA enzyme inhibitors. DEPC water was added to a $20 \mu \mathrm{L}$ total volume. The reaction was performed at $42^{\circ} \mathrm{C}$ for $60 \mathrm{~min}$, followed by $72^{\circ} \mathrm{C}$ for $10 \mathrm{~min}$. The reverse transcription product was stored at $-20^{\circ} \mathrm{C}$ before use.

\section{Real-time PCR}

Using $\beta$-actin as an internal control, Cyt-c and Apaf-1 mRNA expressions were analyzed by real-time PCR. The $50-\mu \mathrm{L}$ reaction system contained $25 \mu \mathrm{L}$ UltraSYBR Mixture, 1 $\mu \mathrm{L}$ forward primer, $1 \mu \mathrm{L}$ reverse primer, $2 \mu \mathrm{L} 10 \mathrm{ng}$ template DNA, and DEPC water. The PCR cycle parameters were $50^{\circ} \mathrm{C}$ for $2 \mathrm{~min}, 95^{\circ} \mathrm{C}$ for $10 \mathrm{~min}$ (pre-denaturation), $95^{\circ} \mathrm{C}$ for $15 \mathrm{~s}$, and $60^{\circ} \mathrm{C}$ for $1 \mathrm{~min}$ for 40 cycles. For melting curve analysis, the parameters were: $95^{\circ} \mathrm{C}$ for $15 \mathrm{~s}$, 
$60^{\circ} \mathrm{C}$ for $1 \mathrm{~min}, 95^{\circ} \mathrm{C}$ for $15 \mathrm{~s}$, and $60^{\circ} \mathrm{C}$ for $15 \mathrm{~s}$. After the reaction was complete, the expressions of Cyt-c and Apaf-1 mRNA were measured by relative quantitative analysis.

\section{Primers}

Three pairs of primers were designed using Primer3 Input 0.4.0: $\beta$-actin forward primer, TGGCACCCAGCACAATGAA; $\beta$-actin reverse primer, CTAAGTCATA GTCCGCCTAGAAGCA; Cyt-c forward primer, GCCTACCC ATTCCAACTTG GTC; Cyt-c reverse primer, AATTATTGAAGCAGATCAGTTTTCG; Apaf-1 forward primer, TACAATCAGGCTCTGGGAGAC; Apaf-1 reverse primer, GTGAACTGGATGTGCCATAC.

\section{Statistical analysis}

Statistical analyses of the results were performed using the SPSS 13.0 software. Measurement data were analyzed using one-way analysis of variance (ANOVA) and the SNK method (for multiple comparisons) in cases where the distribution of the data was normal and the variance showed homogeneity; otherwise, the Dunnett's T3 test was performed for pairwise comparisons. The measurement data are reported as means \pm SD. Statistical significance was determined at $\alpha=0.05$.

\section{RESULTS}

\section{Follicle number, ovarian weight, and apoptotic index}

The numbers of follicles at different stages, ovarian weights, and apoptotic index are shown in Table 1. There were significant differences in the number of growing follicles and the number of mature follicles among groups.

Table 1. Follicle count, ovarian weight, and apoptosis index after treatment.

\begin{tabular}{|c|c|c|c|c|c|c|}
\hline Group & Primordial follicle & Growing follicle & Mature follicle & Total number of follicles & Ovarian weight & Apoptosis index (\%) \\
\hline$\overline{\mathrm{A}}$ & $37.9 \pm 2.9$ & $24.3 \pm 1.3$ & $13.2 \pm 1.3$ & $75.4 \pm 3.1$ & $96.5 \pm 7.1$ & $3.6 \pm 0.7$ \\
\hline B & $35.2 \pm 4.0^{*}$ & $8.9 \pm 1.3$ & $5.5 \pm 1.1$ & $49.6 \pm 4.5^{*}$ & $56.8 \pm 5.4^{*}$ & $65.3 \pm 2.9^{*}$ \\
\hline $\mathrm{C}$ & $39.2 \pm 2.2^{* \# \Delta}$ & $13.6 \pm 1.3$ & $9.2 \pm 1.1$ & $60.5 \pm 3.9^{* \# \Delta}$ & $83.5 \pm 6.7^{* \# \Delta}$ & $35.7 \pm 2.0^{* \# \Delta}$ \\
\hline $\mathrm{D}$ & $36.7 \pm 2.1^{* \Delta}$ & $15.8 \pm 2.1$ & $11.3 \pm 2.0$ & $63.8 \pm 5.1 * \# \Delta$ & $86.8 \pm 10^{* \# \Delta}$ & $37.4 \pm 1.6^{* \# \Delta}$ \\
\hline $\mathrm{E}$ & $58.4 \pm 2.5^{* \#}$ & $6.4 \pm 1.0$ & $2.7 \pm 2.2$ & $67.7 \pm 3.5^{* \#}$ & $54.2 \pm 4.0^{* \#}$ & $30.5 \pm 2.9^{* \#}$ \\
\hline
\end{tabular}

\section{Cyt-c and Apaf-1 protein levels}

The ovaries in groups B, C, and D had higher protein levels of cytoplasmic Cyt-c and Apaf-1 than did ovaries from group A $(\mathrm{P}<0.05)$. The cytoplasmic Cyt-c and Apaf-1 protein levels in group $\mathrm{E}$ were slightly higher than in group $\mathrm{A}$, but the differences were not statistically significant $(\mathrm{P}>0.05)$. The cytoplasmic Cyt-c and Apaf-1 protein levels were lower in groups $\mathrm{C}, \mathrm{D}$, and $\mathrm{E}$ than in group $\mathrm{B}(\mathrm{P}<0.05)$, and those in groups $\mathrm{C}$ and $\mathrm{D}$ were higher than those in group $\mathrm{E}(\mathrm{P}<0.05)$. There was no significant difference in the cytoplasmic Cyt-c and Apaf-1 protein levels between groups $\mathrm{C}$ and $\mathrm{D}(\mathrm{P}>0.05)$ (Figure 1). 


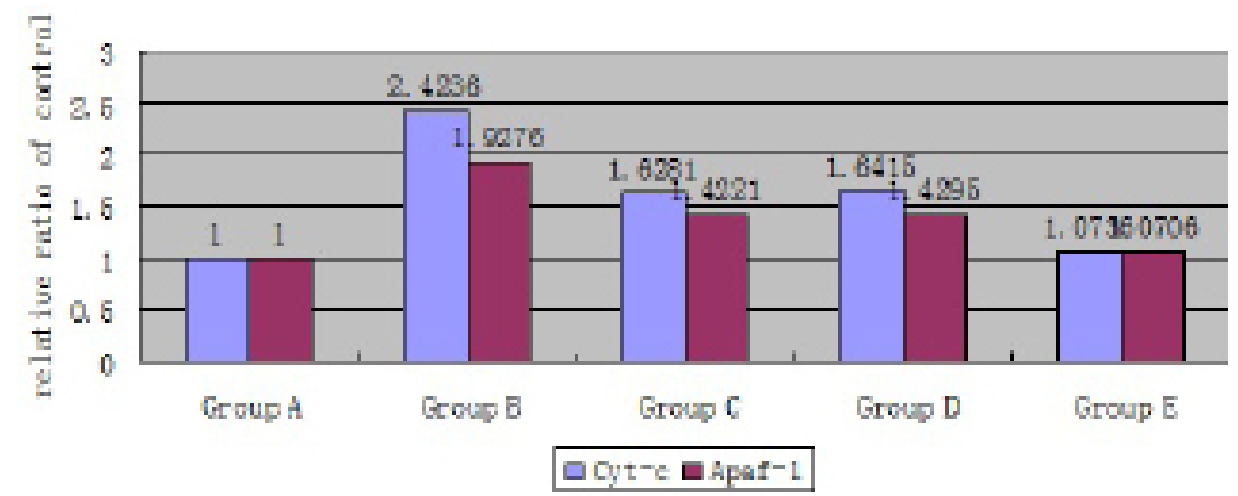

Figure 1. Expression levels of Cyt-c and Apaf-1 protein.

\section{Cyt-c and Apaf-1 mRNA expression levels}

Compared with group A, the Cyt-c and Apaf-1 mRNA expressions in group B were significantly increased, up to five times higher than that in group $\mathrm{A}(\mathrm{P}<0.05)$. The Cyt-c and Apaf-1 mRNA expressions in groups $\mathrm{C}$ and $\mathrm{D}$ were reduced significantly compared with those of group A $(\mathrm{P}<0.05)$. The Cyt-c and Apaf-1 mRNA expressions in group $\mathrm{E}$ did not differ significantly from those of group $\mathrm{A}(\mathrm{P}>0.05)$ (Figure 2).

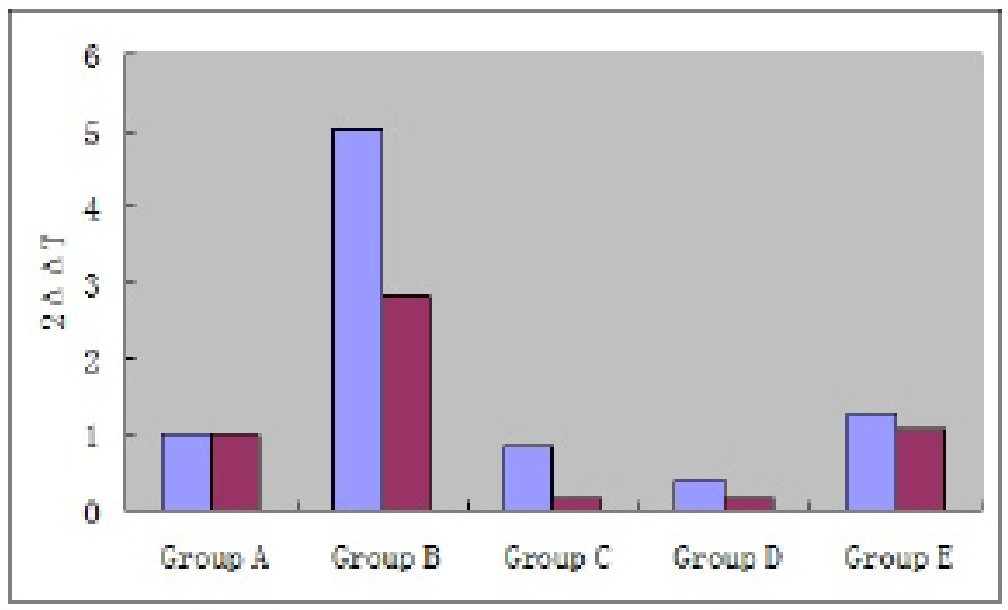

Figure 2. Expression levels of Cyt-c and Apaf-1 mRNA.

Cyt-c and Apaf-1 mRNA expressions were significantly lower in groups C, D, and E compared with group $\mathrm{B}(\mathrm{P}<0.05)$, and the expression levels in groups $\mathrm{C}$ and $\mathrm{D}$ were significantly lower than those in group $\mathrm{E}(\mathrm{P}<0.05)$. There was no significant difference in Cyt-c and Apaf-1 mRNA expression between groups $\mathrm{C}$ and $\mathrm{D}(\mathrm{P}>0.05)$. 


\section{DISCUSSION}

MOGCTs originate from embryonic gonads. Although the disease is of low incidence overall, it is prevalent in children and young women. Surgery combined with postoperative chemotherapy is highly effective in treating this type of tumor, and platinum-based combination chemotherapy can increase the five-year survival rate to $90 \%$. Many patients survive to reproductive age and desire to start families. However, platinum is moderately toxic to ovaries, and long-term use can impair ovarian function, leading to ovarian atrophy and reduced follicular storage capacity, which can affect a patient's quality of life and reproductive capability. The mechanism underlying the anti-tumor and ovary-impairing effects of platinum is via oxidative damage leading to apoptosis, thereby causing a decrease in the number of follicles (Chirino and Pedraza-Chaverri, 2009). Therefore, antagonizing oxidation and regulating cellular apoptosis should be a future direction for developing clinical drug therapies for ovarian and fertility protection.

Apoptosis involves complex cellular mechanisms. Among the various pathways involved in apoptosis is the classical mitochondrial pathway. Many apoptosis-inducing factors, such as oxygen free radicals, can alter the permeability of mitochondrial membranes and the membrane potential, thereby triggering the release of mitochondrial Cyt-c into the cytoplasm (Rehm et al., 2009; Jourdain and Martinou, 2009). Recent studies have shown that Apaf-1 constitutes the core of apoptotic bodies (Yoshida et al., 1998; Feng et al., 2012). Cyt-c binds to and activates Apaf-1, and then combines with Caspase-9 to form apoptotic bodies (Hajra and Liu, 2004; Okamoto et al., 2010); this in turn activates Caspase-9 and creates a cascade of caspase activation, thus initiating the process of apoptosis. In 1997, Zou et al. were the first to isolate and clone the cDNA of Apaf-1 from the cytoplasm of Hela cells. The Apaf-1 gene maps to chromosome $12 \mathrm{q} 23$, and its encoded protein has a molecular weight of approximately $130 \mathrm{kD}$. The carboxy-terminus of the Apaf- 1 protein contains a functional domain composed of 12 WD-40 repeats, through which Apaf-1 binds to Cyt-c. The amino-terminus of the Apaf1 protein contains a functional domain, the CED-3 homologous cysteine caspase recruitment domain (CARD) (Milam et al., 2007). Through CARD, Apaf-1 binds to and activates Caspase-9, thereby initiating the mitochondrial apoptotic pathway (Okamoto et al., 2010). Many apoptosis-regulating factors, such as Bax, Bad, and the Bcl family (Yang et al., 1995; Lasi et al., 2010), exert their functions through the control of this process. As such, Cyt-c and Apaf-1 play key roles in apoptosis.

Growing follicles and mature follicles are sensitive to oxidative damage by cisplatin, whereas primordial follicles are not. GnRH analogues are clinically used to protect ovarian function, primarily through the inhibition of ovarian follicular development. This effect results in the reduction of growing and mature follicles, and in an increase in primordial follicles (Takekida et al., 2003), thereby mitigating cisplatin-induced injury (Meistrich and Shetty, 2008). Ginkgo flavonoids contain hydroxyl ions, which can effectively scavenge oxygen free radicals. Therefore, they are a good plant source of antioxidants (Dias et al., 2008; Hsu et al., 2011). The amifostine structure contains both hydroxyl and thiol groups, which can also play an antioxidant role (Grdina et al., 2009; Fu et al., 2009). In this study, we showed that leuprorelin inhibited follicular development such that follicles became arrested in the primordial stage; it thereby exerted a protective effect on ovaries, and decreased the apoptosis of ovarian cells. Leuprorelin was more effective than Ginkgo flavonoids and amifostine, but had little effect on Cyt-c 
and Apaf-1 protein and mRNA expression levels. Both Ginkgo flavonoids and amifostine manifested protective effects on ovaries, and both showed similar efficacies; the numbers of follicles at various stages were increased compared to the cisplatin group. The ovarian weight was higher and the apoptotic index was lower in the flavonoids and amifostine groups than in the cisplatin group. The mRNA expressions of Cyt-c and the Apaf-1 were downregulated, but the cytosolic Cyt-c and Apaf-1 protein levels were higher than those of the control group, suggesting that the mRNA and protein expressions are differentially regulated by these agents, although this requires further investigation. Previous studies have shown that Ginkgo flavonoids exert a protective effect on cisplatin-induced human ovarian granulosa cell impairment, but maintains synergistic inhibition with cisplatin in PA-1 cells; this suggested that the actions of Ginkgo flavonoids in normal granulosa cells are influenced by different factors than those in tumor cells, which remain to be identified. Studies have also shown that amifostine has different drug distributions in tumorous and normal tissues, enabling it to play protective roles in normal organs while avoiding any negative impacts on the anti-tumor effects of radio- and/or chemotherapy (Fu et al., 2009). Ginkgo flavonoids and amifostine exert their actions by scavenging oxygen free radicals that may exert the cytotoxic effects of cisplatin. Whether these compounds adversely affect chemotherapeutic intervention in patients with malignant tumors has yet to be determined. The routes of drug administration can also affect the efficacies of experimental drugs. The clinically useful Ginkgo flavonoids have two formulations: oral tablets and injections. The Ginkgo flavonoids used in this study were only administered orally. Amifostine is generally administered clinically by intravenous drip; however, in this study, it was administered by intraperitoneal injection. Regarding drug efficacy, intravenous administration generally differs between the intraperitoneal injection and oral administration modes. Whether the routes of drug administration influence the protective effects of these drugs on ovarian function requires further investigation.

\section{Summary}

Our study clearly showed that administration of leuprorelin, Ginkgo flavonoids, or amifostine prior to intraperitoneal injection of cisplatin exerted protective effects on cisplatininduced rat ovarian impairment. The total ovarian follicle counts in all the three treatment groups were higher than those in the cisplatin group, and the apoptotic index and the Cyt-c and Apaf-1 cytoplasmic protein levels were lower than those in the cisplatin group. The efficacy of leuprorelin was comparable to that of Ginkgo flavonoids and amifostine, and the efficacy of Ginkgo flavonoids was equivalent to that of amifostine.

\section{REFERENCES}

Babich H, Ackerman NJ, Burekhovich F, Zuckerbraun HL, et al. (2009). Gingko biloba leaf extract induces oxidative stress in carcinoma HSC-2 cells. Toxicol. In Vitro 23: 992-999.

Camats N, García F, Parrilla JJ, Calaf J, et al. (2009). The GnRH analogue triptorelin confers ovarian radio-protection to adult female rats. Mutat. Res. 669: 67-79.

Chirino YI and Pedraza-Chaverri J (2009). Role of oxidative and nitrosative stress in cisplatin-induced nephrotoxicity. Exp. Toxicol. Pathol. 61: 223-242.

Dias MC, Rodrigues MA, Reimberg MC and Barbisan LF (2008). Protective effects of Ginkgo biloba against rat liver carcinogenesis. Chem. Biol. Interact. 173: 32-42.

Feng R, Han J, Ziegler J, Yang M, et al. (2012). Apaf-1 deficiency confers resistance to ultraviolet-induced apoptosis 
in mouse embryonic fibroblasts by disrupting reactive oxygen species amplification production and mitochondrial pathway. Free Radic. Biol. Med. 52: 889-897.

Fu P, Birukova AA, Xing J, Sammani S, et al. (2009). Amifostine reduces lung vascular permeability via suppression of inflammatory signalling. Eur. Respir. J. 33: 612-624.

Grdina DJ, Murley JS, Kataoka Y, Baker KL, et al. (2009). Amifostine induces antioxidant enzymatic activities in normal tissues and a transplantable tumor that can affect radiation response. Int. J. Radiat. Oncol. Biol. Phys. 73: 886-896.

Hajra KM and Liu JR (2004). Apoptosome dysfunction in human cancer. Apoptosis 9: 691-704.

Hsu CL, Shyu MH, Lin JA and Yen GC (2011). Cytotoxic effects of geranyl flavonoid derivatives from the fruit of Artocarpus communis in SK-Hep-1 human hepatocellular carcinoma cells. Food Chem. 127: 127-134.

Jourdain A and Martinou JC (2009). Mitochondrial outer-membrane permeabilization and remodelling in apoptosis. Int. J. Biochem. Cell Biol. 41: 1884-1889.

Lasi M, Pauly B, Schmidt N, Cikala M, et al. (2010). The molecular cell death machinery in the simple cnidarian Hydra includes an expanded caspase family and pro- and anti-apoptotic Bcl-2 proteins. Cell Res. 20: 812-825.

Li P, Nijhawan D, Budihardjo I, Srinivasula SM, et al. (1997). Cytochrome c and dATP-dependent formation of Apaf-1/ caspase-9 complex initiates an apoptotic protease cascade. Cell 91: 479-489.

Liu XP, Goldring CE, Wang HY, Copple IM, et al. (2009). Extract of Ginkgo biloba induces glutathione-S-transferase subunit-P1 in vitro. Phytomedicine 16: 451-455.

Meistrich ML and Shetty G (2008). Hormonal suppression for fertility preservation in males and females. Reproduction 136: 691-701.

Milam SL, Nicely NI, Feeney B, Mattos C, et al. (2007). Rapid folding and unfolding of Apaf-1 CARD. J. Mol. Biol. 369: 290-304.

Murley JS, Kataoka Y and Grdina DJ (2012). Amifostine and the Endogenous Cellular Antioxidant Enzyme Manganese Superoxide Dismutase in Radioprotection. In: Oxidative Stress Cancer Biology and Therapy (Spitz DR, Dornfeld KJ, Krishnan K and Gius D, eds.). Humana Press, New York, 149-168.

Okamoto M, Koga S and Tatsuka M (2010). Differential regulation of caspase-9 by ionizing radiation- and UV-induced apoptotic pathways in thymic cells. Mutat. Res. 688: 78-87.

Ozcelik B, Turkyilmaz C, Ozgun MT, Serin IS, et al. (2010). Prevention of paclitaxel and cisplatin induced ovarian damage in rats by a gonadotropin-releasing hormone agonist. Fertil. Steril. 93: 1609-1614.

Pinto MS, Kwon YI, Apostolidis E, Lajolo FM, et al. (2009). Potential of Ginkgo biloba L. leaves in the management of hyperglycemia and hypertension using in vitro models. Bioresour. Technol. 100: 6599-6609.

Rehm M, Huber HJ, Hellwig CT, Anguissola S, et al. (2009). Dynamics of outer mitochondrial membrane permeabilization during apoptosis. Cell Death. Differ. 16: 613-623.

Takekida S, Matsuo H and Maruo T (2003). GnRH agonist action on granulosa cells at varying follicular stages. Mol. Cell Endocrinol. 202: 155-164.

Yang E, Zha J, Jockel J, Boise LH, et al. (1995). Bad, a heterodimeric partner for Bcl-XL and Bcl-2, displaces Bax and promotes cell death. Cell 80: 285-291.

Yoshida H, Kong YY, Yoshida R, Elia AJ, et al. (1998). Apaf1 is required for mitochondrial pathways of apoptosis and brain development. Cell 94: 739-750.

Zou H, Henzel WJ, Liu X, Lutschg A, et al. (1997). Apaf-1, a human protein homologous to C. elegans CED-4, participates in cytochrome c-dependent activation of caspase-3. Cell 90: 405-413. 